\title{
Leucemia de células plasmáticas: variante rara del mieloma múltiple. Caso clínico
}

\author{
P. KHOSRAVI SHAHI
}

Servicio de Oncología Médica. Hospital General Universitario Gregorio Marañón. Madrid.

\section{RESUMEN}

La leucemia de células plasmáticas es una variante infrecuente del mieloma múltiple (2-3\%) con un curso clínico agresivo y una corta supervivencia. Se define por la presencia de células plasmáticas en más del $20 \%$ de la totalidad de los leucocitos de la sangre periférica y más de 2000 células plasmáticas por microlito en la sangre periférica.

Presentamos el caso de un varón de 32 años con dolor intenso en hemitórax izquierdo, con una pequeña adenopatía laterocervical derecha, hepatomegalia y 8.800 leucocitos/ul con $33 \%$ linfocitos (la mayoría de ellos de aspecto plasmocitoide), y $40 \%$ células plasmáticas; $10,8 \mathrm{~g} / \mathrm{dl}$ de proteínas totales y un pico monoclonal en banda gamma. La biopsia de médula ósea evidenció una plasmocitosis medular del 40-50\%. La Inmunofijación en suero demostró una paraproteína IgG-Kappa.

PALABRAS CLAVE: Leucemia de células plasmáticas. Mieloma múltiple. C-VAD. Componente M.
PLASMA CELL LEUKAEMIA: A RARE VARIANT OF MULTIPLE MYELOMA. A CASE REPORT

Khosravi Shahi P. Leucemia de células plasmáticas: variante rara del mieloma múltiple. Caso clínico. An Med Interna (Madrid) 2005; 22: 532-534.

\section{INTRODUCCIÓN}

El mieloma múltiple es una neoplasia maligna de células plasmáticas, que representa el $15 \%$ de las neoplasias hematológicas malignas. Suele ser una enfermedad de edades avanzadas, con una mediana de edad al diagnóstico de 65-70 años, sin predominio sexual evidente (1). Las manifestaciones clínicas del mieloma múltiple incluyen dolor óseo, fracturas patológicas, insuficiencia renal, hipercalcemia, lesiones osteolíticas, osteoporosis, anemia normocítica y normocroma, con presencia de una proteína monoclonal (paraproteína o componente $\mathrm{M}$ ) en suero y/u orina.

Los criterios diagnósticos del mieloma múltiple incluyen:

1. Criterios mayores:

a) Plasmocitoma tisular por biopsia.

b) Plasmocitosis medular mayor del $30 \%$.

\begin{abstract}
Plasma cell leukaemia is a rare variant of multiple myeloma (2-3\%), with an aggressive disease with short survival. It is defined as circulating peripheral blood plasma cells exceeding 2.000/ul and $20 \%$ of peripheral blood white cells.

We present the case of 32-years-old man with left chest-wall pain, hepatomegaly, righ cervical adenopathy, 8800 leukocytes/ul with $33 \%$ of lymphocytes and $40 \%$ of plasma cell, $10,8 \mathrm{~g} / \mathrm{dl}$ of proteins and a monoclonal hypergammaglobulinemia. Bone marrow biopsy showed 40-50 \% of intramedullary plasma cell. There was a Ig G-kappa paraproteinemia.
\end{abstract}

KEY WORDS: Plasma cell leukaemia. Multiple myeloma. C-VAD. M-component.

Trabajo aceptado: 00 de marzo de 2005

Correspondencia: Parham Khosravi Shahi. Servicio de Oncología Médica. Hospital General Universitario Gregorio Marañón. Doctor Esquerdo, 46,28007 Madrid. e-mail: drkhosravi@ hotmail.com 
autólogo de médula ósea, la talidomida (2,3), el CC-5013 (Revimid) (4), PS-341 (Velcade) un inhibidor de proteosoma (5) e incluso el trasplante alogénico de médula ósea (6).

\section{CASO APORTADO}

Presentamos el caso de un varón de 32 años, sin alergias medicamentosas conocidas, con el único antecedente personal de reumatismo poliarticular en la infancia. Ingresa desde las urgencias por dolor intenso en hemitórax izquierdo, que no se modifica con los movimientos respiratorios, ni con los cambios posturales, sin tos productiva, ni disnea, y sin otra sintomatología acompañante.

En la exploración física destaca una pequeña adenopatía laterocervical derecha inespecífica, con una hepatomegalia de unos $3 \mathrm{~cm}$ desde el reborde costal, sin otros hallazgos de interés.

Presentando las siguientes pruebas complementarias:

\section{PRUEBAS COMPLEMENTARIAS BÁSICAS}

Hemograma y frotis de sangre periférica: Hemoglobina 13,3 g/dl, Plaquetas 281.000/ul, Leucocitos $8.800 / \mathrm{ul}$ con $23 \%$ de segmentados, $1 \%$ cayados, $1 \%$ metamielocitos, $2 \%$ monocitos, $33 \%$ linfocitos (la mayoría de ellos de aspecto plasmocitoide), y $40 \%$ células plasmáticas, algunas de las cuales binucleadas de tamaño grande.

Bioquímica: Creatinina 1,2 mg/dl, Urea $52 \mathrm{mg} / \mathrm{dl}$, (aclaramiento de creatinina de $59 \mathrm{ml} / \mathrm{min}$ ), proteínas totales $10,8 \mathrm{~g} / \mathrm{dl}$, calcio total $9,8 \mathrm{mg} / \mathrm{dl}$, resto normal.

Proteinograma: pico monoclonal en banda gamma.

Coagulación: APTT 33,6 segundos, INR 1,35.

Examen básico de orina: Proteínas positivo, con presencia de mucina en el sedimento.

Radiografía de tórax: Pequeña imagen nodular calcificada en lóbulo inferior izquierdo, probable granuloma calcificado.

\section{PRUEBAS COMPLEMENTARIAS ESPECÍFICAS}

Inmunofenotipo en sangre periférica: El $45 \%$ del recuento leucocitario total presenta un inmunofenotipo anómalo: CD45+, CD38+, CD138+, CD56+, CD19-, CD20-, CD5, CD10-, CD23-, Cd79b-, sIg-.

Aspirado de médula ósea: Presencia de células plasmáticas en una proporción del $50 \%$ de la celularidad total, de tamaño heterogéneo predominando elementos de talla intermedia. Frecuentes células binucleadas y trinucleadas.

Biopsia de médula ósea: Infiltración intersticial multifocal del parénquima medular por células plasmáticas plasmoblásticas IGKappa. Plasmocitosis medular del 40-50\%. Material amiloide negativo.

Beta2-microglobulina: $7,3 \mathrm{mg} / \mathrm{dl}$.

Serie ósea: Sin evidencia de lesiones osteolíticas.

Inmunoelectroforesis en suero: $\operatorname{IgG} 4.390 \mathrm{mg} / \mathrm{dl}, \mathrm{IgA}$ 14,5mg/dl, IgM 4,17 mg/dl. Inmunofijación en suero: Paraproteína IgG-Kappa.

Inmunoelectroforesis en orina: Proteinuria de cadenas ligeras (Bence-Jones) de $1.310 \mathrm{mg}$ en 24 horas, para paraproteína IgG-Kappa y cadenas ligeras Kappa libres.

Serología $V H B, V H C, V I H$ : negativos.

Ecografía abdominal: Hepatomegalia, sin lesiones focales hepatoesplénicas. No hay evidencia de adenopatías intrabdominales, ni líquido libre intraperitoneal, resto sin alteraciones.

Diagnóstico: El paciente presenta un cuadro compatible con un mieloma múltiple en su variante leucemia de células plasmáticas primaria.
Tratamiento: Dado la edad del paciente se decide trasplante autólogo de células progenitoras de sangre periférica. Para lo cual se inició quimioterapia de inducción con el esquema C-VAD.

\section{DISCUSIÓN}

La leucemia de células plasmáticas es una variante rara del mieloma múltiple, constituyendo el 2-3\% de todos los mielomas (7). Se trata de un mieloma múltiple de alta agresividad con una supervivencia corta, que debe cumplir los dos siguientes criterios diagnósticos: a) Presencia de células plasmáticas en más del $20 \%$ de la totalidad de los leucocitos en sangre periférica; b) Presencia de células plasmáticas en número superior a 2.000/ul en sangre periférica.

La leucemia de células plasmáticas puede clasificarse en dos subtipos:

1. Leucemia de células plasmáticas primaria: cuando la leucemización está presente ya en el momento diagnóstico, como es en nuestro caso.

2. Leucemia de células plasmáticas secundaria: cuando aparece como consecuencia de la transformación de un mieloma múltiple previo.

La leucemia de células plasmáticas primaria se caracteriza por aparecer en pacientes más jóvenes, con un pronóstico mejor que en los secundarios, con una mediana de supervivencia de unos 6,8 meses. Las lesiones osteolíticas, la hipercalcemia, las fracturas patológicas y el dolor óseo son menos frecuente en las leucemias de células plasmáticas primaria, presentando con una mayor frecuencia organomegalias (hepatoesplenomegalia) y adenopatías. El componente M sérico y/o urinario suele ser de menor cuantía que en los mielomas múltiples típicos, mientras que la presencia de insuficiencia renal es común.

Las células plasmáticas circulantes pueden adoptar una morfología muy variable, desde formas maduras hasta formas inmaduras similares a los mieloblastos, y en algunos casos tienen una morfología linfoide. El inmunofenotipo de las células plasmáticas circulantes es similar al mieloma múltiple (cIg+, sIg-, CD19-, CD20-, CD38+), pero generalmente el CD56 es negativo; y con frecuencia las células expresan sólo cadenas ligeras, Ig E o Ig D.

En nuestro caso el paciente presenta varios criterios diagnósticos:

1. Paraproteinemia IgG-Kappa de $4.390 \mathrm{mg} / \mathrm{dl}$ y paraproteinuria de $1,310 \mathrm{~g} / \mathrm{dl}$ en 24 horas.

2. Plasmocitosis medular del 40-50\%.

3. Disminución de las inmunoglobulinas normales por debajo del $50 \%$ del valor normal.

4. Células plasmáticas en un porcentaje del $40 \%$ de la celularidad de la sangre periférica y más del 2.000 células plasmáticas/ul en sangre periférica.

El tratamiento de la leucemia de células plasmáticas incluye el tratamiento con VAD, pulsos de dexametasona, agentes alquilantes e incluso el trasplante autólogo de médula ósea (9-11).

En nuestro caso dado el buen estado general del paciente, la edad y la ausencia de un hermano histocompatible, nos hemos decantado por una quimioterapia de inducción con el esquema C-VAD (Ciclofosfamida, Vincristina, Adriamicina y Dexametasona), seguido de movilización de células progenitoras hematopoyéticas de sangre periférica y posterior quimioterapia de alta dosis y trasplante autólogo de médula ósea. 


\section{Bibliografía}

1. Bataille R, Harousseau J. Multiple myeloma. N Engl J Med 1997; 336:1657-1664.

2. Barlogie B, Tricot G, Anaissie E. Thalidomide in the managment of multiple myeloma. Semin Oncol 2002; 28: 577-582.

3. Singhal S, Mehta J. Antitumor activity of thalidomide in refractory multiple myeloma. N Engl J Med 1999; 341: 1565-1571.

4. Richardson P, Schlossman RL, Weller. Immunomodulatory drug CC5013 overcomes drug resistance and is well tolerated in patients with relapsed multiple myeloma. Blood 2002; 100: 3063-3067.

5. Richardson P, Barlogie B, Berenson. A phase II multicenter study of the proteasome inhibitor bortezomib (Velcade, formally PS-341) in multiple myeloma patients with relapsed/refractory disease. Blood 2002; 100: $104-105$
6. Bensinger W, Maloney D, Storb R. Allogeneic hematopoietic cell transplantation for multiple myeloma. Semin Hematol 2001; 38: 243-249.

7. García-Sanz R, Orfao A, González M. Primary plasma cell leukemia: clinical, immunophenotypic, DNA ploidy, and cytogenetic characteristics. Blood 1999; 93: 1032-1037.

8. Noel P, Kyle RA. Plasma cell leukemia: An evaluation ofresponse to therapy. Am J Med 1987; 83: 1062-1068.

9. Anderson H, Scarffe JH, Ransom M. VAD chemotherapy as remission induction for multiple myeloma. Br J Cancer 1995; 71: 326-330.

10. Barlogie B, Shaughnessy J, Tricot G, Jacobson J, Zangari M, Anaissie E et al. Treatment of multiple myeloma. Blood 2004; 103: 20-32.

11. McElwain TJ, Powles RL. High -dose intravenous melphalan for plasma cell leukemia and myeloma. Lancet 1983; 2:822-824. 